\title{
Metassíntese Qualitativa dos Referenciais Teóricos na Formação de Professores no Campo Multiplicativo
}

\author{
Qualitative metasynthesis of theorical frameworks in the teacher training at \\ multiplicative field
}

\author{
Edvonete Souza de Alencar ${ }^{1}$ \\ Saddo Ag Almouloud ${ }^{2}$
}

\section{Resumo}

Este artigo investiga os referenciais teóricos que sustentam pesquisas brasileiras, publicadas entre 1997 e 2015 , relativas à formação contínua de professores dos anos iniciais do Ensino Fundamental sobre o Campo Conceitual Multiplicativo. Para sua realização, fizemos uma metassíntese qualitativa. A seleção de pesquisas ocorreu a partir do site do Banco de Teses da Capes, mediante uso de expressões relacionadas ao objetivo do estudo, obtendo, por meio de filtros, 27 pesquisas. Com este grupo, buscamos os referenciais teóricos mais citados pelas investigações: Shulman e Vergnaud. Foram encontradas nove pesquisas que utilizaram os dois referenciais teóricos, passando a ser este o corpus para a realização de uma metassíntese qualitativa. Os resultados indicam que há aspectos teóricos que não são abordados pelas investigações como: o modelo de raciocínio e ação de Shulman e o aprofundamento das situações-problema de Vergnaud.

Palavras-chave: Referenciais teóricos; Formação de professores; Campo Conceitual Multiplicativo.

\begin{abstract}
This article investigates the theoretical references that support Brazilian researches, published between 1997 and 2015 , on the continuous training of teachers of the early years of Elementary School on the Multiplicative Conceptual Field. To do so, we performed a qualitative meta-synthesis. The research selection was carried out on the Capes Theses Bank website, through use of expressions related to the purpose of the study, obtaining through these filters, 27 researches. With this, we looked for references mostly used by the theoretical investigations: Shulman and Vergnaud. Nine of those researches had made use of both theoretical references, forming the group for conducting a qualitative meta-synthesis. The results indicate that there are theoretical aspects that are not covered by the investigations, such as: the model of thought and action of Shulman and the exploration of problem situations of Vergnaud.
\end{abstract}

Keywords: Theoretical references; Teachers Training; Multiplicative Conceptual Field

\footnotetext{
${ }^{1}$ Doutora em Educação Matemática pela PUC-SP. Professora Adjunta da Universidade Federal da Grande Dourados - Faculdade de Educação, Brasil. E-mail:edvonete.s.alencar@hotmail.com.

${ }^{2}$ Doutor em Mathematiques et Applications pela Universitè de Rennes I em 1992. Professor na Pontifícia Universidade Católica de São Paulo e na Fundação Santo André, Brasil. E-mail:saddoag@gmail.com
} 


\section{Introdução}

É preciso ver o que não foi visto, ver outra vez o que se viu já, ver na primavera o que se virá no verão, ver de dia o que se viu de noite, com o sol onde primeiramente a chuva caía, ver a seara verde, o fruto maduro, a pedra que mudou de lugar, a sombra que aqui não estava. É preciso voltar aos passos que foram dados para repetir e traçar caminhos novos ao lado deles (José Saramago,1985, p.387)

O trecho da obra "Viagem a Portugal" de José Saramago, escritor português que discorre sobre o olhar para o conhecido, para os lugares, costumes e paisagens de seu país com outros olhos, com o olhar de viajante. Assim, este fragmento nos leva a refletir sobre as pesquisas que realizam revisões sistemáticas. Essas, por sua vez, também necessitam ter o olhar de pesquisador, observando o que já foi exposto e investigado, para poder extrair destas pesquisas um novo conhecimento.

Neste artigo, apresentamos um recorte da pesquisa de Alencar (2016), mais especificamente, uma das modalidades de revisão sistemática denominada metassíntese qualitativa. Mostraremos os referenciais teóricos que sustentam pesquisas sobre a formação contínua de professores dos anos iniciais no campo conceitual multiplicativo e como são utilizados pelas investigações.

A leitura de alguns estados da arte, entre eles os trabalhos de André (2002) e Brzezinski (2006), que investigaram a formação de professores, proporcionou-nos uma visão geral sobre os estudos da área. Percebemos que nenhum deles focaliza a formação de professores de Matemática e quiçá os referenciais teóricos que são utilizados por estas investigações.

Os pesquisadores Melo e Fiorentini (2008) indicam o aumento do número de estudos sobre formação de professores que ensinam Matemática e mostram como esse fato proporcionou uma "diversidade teórica" (Melo e Fiorentini, 2008, p. 6). Revelam ainda a necessidade de realização de estudos mais aprofundados sobre a temática (Melo e Fiorentini, 2008, p. 12).

Assim, ao observarmos que os referenciais teóricos são a base das investigações e que, até então, não haviam sido metassintetizados em outros estudos. Por esse motivo, que escolhemos realizar uma metassíntese qualitativa dos referenciais teóricos que sustentam pesquisas. Evidenciamos como estes foram utilizados nas investigações, para mostrar assim semelhanças, diferenças e possíveis complementariedades aos teóricos.

Nosso objetivo foi investigar os referenciais teóricos que sustentam pesquisas brasileiras, publicadas entre 1997 a 2015, a respeito da formação contínua de professores dos anos iniciais do Ensino Fundamental sobre o Campo Conceitual Multiplicativo.

A questão norteadora de nossa investigação foi verificar se: "Há semelhanças, diferenças e complementariedades na maneira como as pesquisas empregaram as ideias originais dos referenciais teóricos?" 
DOI: http://dx.doi.org/10.20396/zet.v25i3.8647539

Consideramos este questionamento importante, pois nos permitirá notar como as pesquisas vêm interpretando e usando os referenciais teóricos e estes dados servirão de base para que outras investigações, que irão abordar essa temática, as utilizem.

Especificamente nesse artigo, apresentamos um recorte da tese de Alencar (2016) evidenciando uma das categorias de cada referencial teórico, com o objetivo de observar se há semelhanças, diferenças e complementariedades sobre como cada referencial teórico mais citado e/ou mencionado é utilizado pelas investigações.

\section{Metassíntese qualitativa}

A metassíntese qualitativa é uma metodologia oriunda de pesquisas internacionais, sendo mais utilizada e conhecida na área da saúde. Os estudos nas demais áreas surgiram especificamente no final da década de 90 pela Fundação Cochrane, que estabeleceu o "Qualitative Reserch Methods Working Group", que dá orientações metodológicas a pesquisadores que utilizam as revisões sistemáticas de acordo com os padrões definidos pela instituição.

Apresentamos assim algumas considerações e definições elucidadas por pesquisadores sobre a metassíntese qualitativa.

Matheus (2009) define a metassíntese qualitativa como a "integração interpretativa de achados qualitativos (derivados de estudos fenomenológicos etnográficos, da teoria fundamentada dos dados e outros), que são a síntese interpretativa dos dados" (p.544). Menciona que as novas interpretações não estão explicitas nos resultados primários analisados. Os estudos primários são, portanto, as amostras dos dados como o todo.

Assim essa nova interpretação "não é uma revisão resumida com características desvinculadas daquele evento ou daquela experiência, mas sim integra os dados a fim de alcançar um nível teórico mais elevado". (Matheus, 2009, p.544)

A metassíntese qualitativa pode ser desenvolvida por meio de relações entre as pesquisas, realizando-se comparações, observando semelhanças e diferenças entre os dados recolhidos das investigações.

Fiorentini (2013) nos diz que a metassíntese qualitativa:

visa produzir interpretações ampliadas de resultados ou achados de estudos qualitativos obtidos por estudos primários (como são as dissertações, teses e pesquisas de professores), os quais são selecionados atendendo a um interesse específico do pesquisador acerca de um fenômeno a ser investigado e/ ou teorizado (Fiorentini, 2013, p.78)

O autor menciona que para a realização da metassíntese qualitativa e desenvolvimento de uma nova interpretação sobre o tema é preciso que ocorra a metainterpretação, no qual o pesquisador reinterpreta as interpretações contidas nas dissertações e teses analisadas.

Em consonância com o que é mencionado nos estudos de Matheus (2009) e Fiorentini (2013), Vosgerau e Romanowski (2014) menciona que para que haja uma visão 
DOI: http://dx.doi.org/10.20396/zet.v25i3.8647539

interpretativa, é preciso que os resultados encontrados nas análises sejam agrupados e reagrupados por semelhanças, na tentativa de responder à questão norteadora da pesquisa.

Salientamos que a metassíntese qualitativa diferencia-se das outras modalidades de revisão sistemática. Essa diferenciação foi abordada por Maranhão e Manrique (2014), que relatam que "os estados da arte e os estados do conhecimento requerem a coleta de muitos estudos, o que não acontece com a metanálise qualitativa - em lugar de partir de amplitude, ela parte de poucos estudos para buscar ampliação, generalização" (p. 428). Do mesmo modo, diferenciam a metanálise da metassíntese qualitativa. Assim a metassíntese qualitativa é também realizada por meio de poucos estudos e a seleção das pesquisas segue critério pessoal do pesquisador e utiliza interpretações das investigações. Nesta pesquisa, a metassíntese realizada utilizou-se da tríade: 1) interpretações contidas nas dissertações e teses; 2) artigos e textos originais dos referenciais teóricos e 3) interpretação do pesquisador.

\section{A Pesquisa}

A busca pelas pesquisas a serem metassintetizadas foi realizada no site do Banco de Teses da Capes, no dia 23 de julho de 2016. Para isso, utilizamos as expressões "Formação de Professores" e "Campo Conceitual Multiplicativo" em títulos, resumos ou palavras-chave, nos programas de Educação e Educação Matemática, com área de concentração em Educação Matemática, o que resultou em 329 dissertações e teses. Com a leitura dos resumos, selecionamos as investigações que mencionavam "Formação Contínua e Anos Iniciais" e encontramos 27 pesquisas, sendo 20 dissertações e 7 teses.

Com este grupo de 27 pesquisas, realizamos o procedimento arrazoado bibliográfico. A palavra "arrazoado", segundo Ferreira (2012), refere-se à argumentação e à defesa de algo ou apresentação dos motivos para a sua realização. Consideramos assim, que o arrazoado bibliográfico se refere a uma busca razoável das referências teóricas utilizadas pelas pesquisas selecionadas. Esse procedimento já foi realizado na tese de Maia (2013). Assim, nessa tese, observamos a frequência de citações e/ou menções que apareciam pelo menos nas análises e na problemática (e/ou quadro teórico) de cada uma das referências teóricas presentes nas investigações. O gráfico 1 apresenta, entre outros, os referenciais teóricos mais utilizados. Em azul, temos as menções e /ou citações que aparecem nas análises; em vermelho, as que aparecem na problemática e/ou no quadro teórico. 
DOI: http://dx.doi.org/10.20396/zet.v25i3.8647539

Gráfico 1- Frequência total das obras teóricas mencionadas e/ ou citadas nas 27 pesquisas.

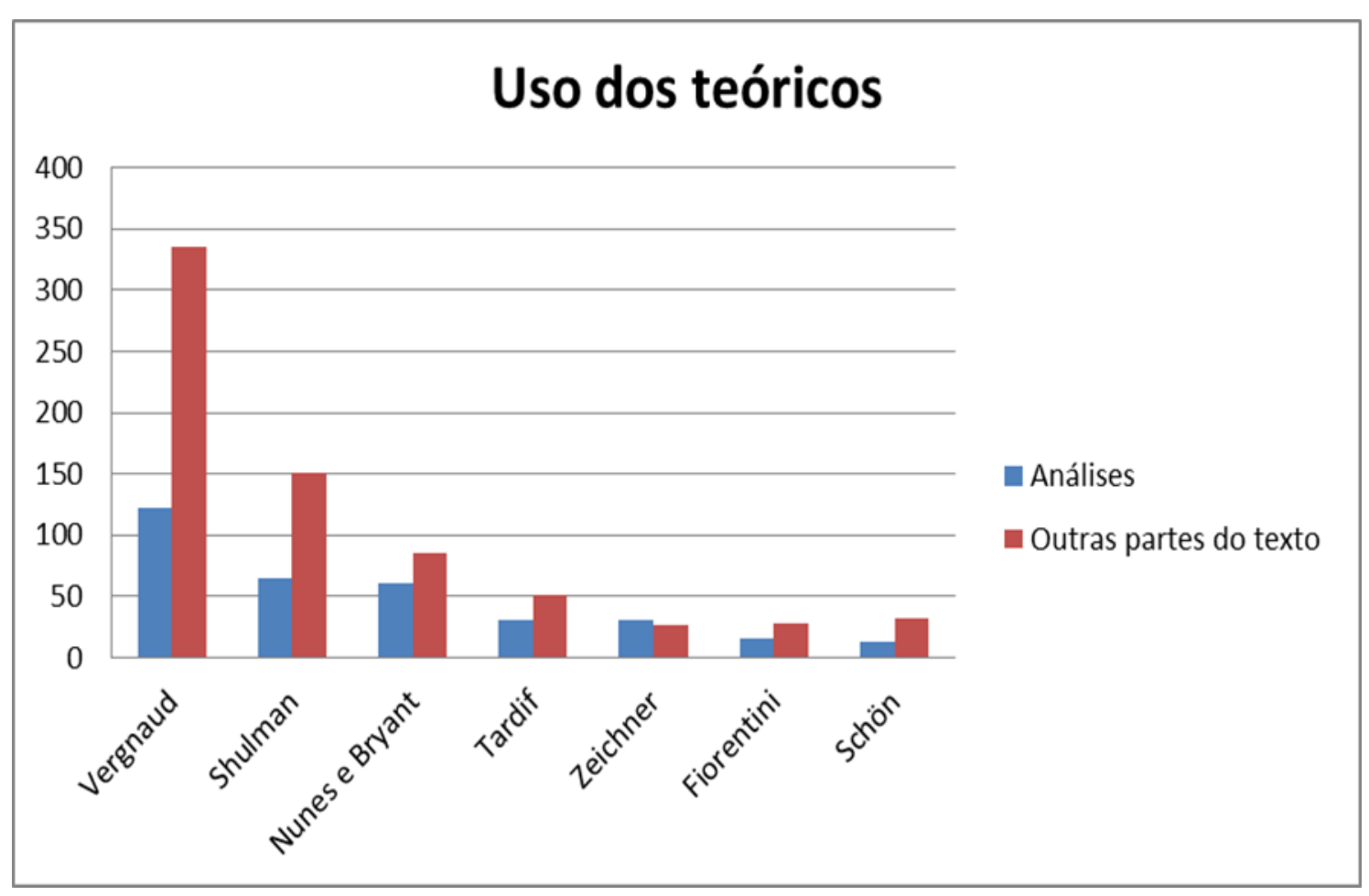

Fonte: Alencar (2016, p.46)

Com isso, notamos que os referenciais teóricos mais citados e/ou mencionados foram Shulman e Vergnaud. Assim, para realizar a metassíntese qualitativa, buscamos selecionar as pesquisas que utilizam Vergnaud e Shulman. Identificamos nove pesquisas (6 dissertações e 3 Teses) que são apresentadas no quadro 1, a seguir:

Quadro 1 - Grupo de nove pesquisas selecionadas

\begin{tabular}{|l|l|l|c|c|}
\hline \multicolumn{1}{|c|}{ Título } & Autor/Ano & Instit. & D/T & Origem \\
\hline $\begin{array}{l}\text { O conceito de fração em seus diferentes significados: } \\
\text { um estudo diagnóstico junto a professores que atuam } \\
\text { no Ensino Fundamental. }\end{array}$ & $\begin{array}{l}\text { Santos, A. } \\
(2005)\end{array}$ & PUCSP & D & SP \\
\hline $\begin{array}{l}\text { As dificuldades na aprendizagem da divisão: análise } \\
\text { da produção de erros dos alunos do Ensino } \\
\text { Fundamental e sua relação com o ensino praticado } \\
\text { pelos professores. }\end{array}$ & $\begin{array}{l}\text { Campos, E. } \\
2007\end{array}$ & UCDB & D & MS \\
\hline $\begin{array}{l}\text { O desafio do desenvolvimento profissional docente: } \\
\text { análise da formação continuada de um grupo de } \\
\text { professores das séries iniciais do Ensino } \\
\text { Fundamental, tendo como objeto de discussão o } \\
\text { processo de ensino e aprendizagem das frações. }\end{array}$ & $\begin{array}{l}\text { Silva, A. G } \\
(2007)\end{array}$ & PUCSP & T & SP \\
\hline
\end{tabular}

\footnotetext{
${ }^{3}$ Para as siglas: D - Dissertação, T - Tese
} 
DOI: http://dx.doi.org/10.20396/zet.v25i3.8647539

\begin{tabular}{|l|l|l|l|l|}
\hline $\begin{array}{l}\text { A formação docente e onsino de problemas } \\
\text { combinatórios: diversos olhares, diferentes } \\
\text { conhecimentos. }\end{array}$ & $\begin{array}{l}\text { Rocha, C. } \\
(2011)\end{array}$ & UFPE & D & PE \\
\hline $\begin{array}{l}\text { Conhecimento profissional docente de professores do } \\
\text { 5. } \text { ano em uma escola com bom desempenho em } \\
\text { Matemática: o caso das estruturas multiplicativas. }\end{array}$ & $\begin{array}{l}\text { Alencar, E. } \\
(2012)\end{array}$ & UNIBAN & D & SP \\
\hline $\begin{array}{l}\text { As potencialidades de um processo formativo para a } \\
\text { reflexão na e sobre a prática de uma professora das } \\
\text { séries iniciais: um estudo de caso. }\end{array}$ & $\begin{array}{l}\text { Merlini, V. } \\
(2012)\end{array}$ & PUCSP & T & SP \\
\hline $\begin{array}{l}\text { Processos de formação colaborativa com foco no } \\
\text { Campo Multiplicativo: um caminho possível com } \\
\text { professoras polivalentes. }\end{array}$ & $\begin{array}{l}\text { Santos, A. } \\
\text { (2012) }\end{array}$ & PUCSP & T & SP \\
\hline $\begin{array}{l}\text { Raciocínio combinatório na resolução de problemas } \\
\text { nos anos iniciais do ensino fundamental: um estudo } \\
\text { com professores. }\end{array}$ & $\begin{array}{l}\text { Oliveira, E. } \\
\text { (2014) }\end{array}$ & PUCSP & D & SP \\
\hline $\begin{array}{l}\text { Intervenções didáticas no Ensino de Frações e as } \\
\text { formas de professores. }\end{array}$ & $\begin{array}{l}\text { Silva Junior, } \\
\text { F. (2015) }\end{array}$ & UNIAN & D & SP \\
\hline
\end{tabular}

Fonte: Alencar (2016, p.51-52)

Antes de proceder a metassíntese desses trabalhos, consideramos importante apresentar um breve resumo de cada investigação.

Santos (2005) investigou as concepções de fração de professores dos anos iniciais do Ensino Fundamental e especialistas da área. O autor realizou uma pesquisa de campo com 67 docentes da área em sete escolas públicas do Governo do Estado de São Paulo, pedindo aos professores que criassem problemas envolvendo frações e depois os resolvessem. As análises dos dados foram realizadas observando os enunciados criados pelos docentes e como eles resolviam os problemas. Os resultados obtidos pela pesquisa apontaram que os professores e os especialistas da área, ao elaborar situações-problema, tendiam a valorizar o operador multiplicativo da fração. Já ao resolver os problemas, eles demonstraram valorizar as resoluções procedimentais. $\mathrm{O}$ autor concluiu que não percebeu diferença entre as concepções dos professores graduados em Pedagogia e dos especialistas em Matemática a respeito das frações, tanto na elaboração como na resolução de problemas. Inferiu ainda que as concepções desses docentes provavelmente estejam ligadas as suas experiências como estudantes no Ensino Fundamental.

Campos (2007) investigou os erros produzidos por alunos de $5^{\circ}, 6^{\circ}$ e $8^{\circ}$ anos em divisão e suas relações com o ensino desenvolvido por seus professores. Para o desenvolvimento desse estudo, foram investigados 45 alunos da rede pública de Campo Grande (MS) e três professores de cada ano. Essa escola foi selecionada para a investigação por apresentar baixo rendimento em Matemática e já ser conhecida pela pesquisadora. Inicialmente a autora realizou testes com oito questões com os alunos. Os problemas eram 
DOI: http://dx.doi.org/10.20396/zet.v25i3.8647539

divididos entre aqueles contendo ideias de divisão e partição e problemas criados pelos próprios alunos. Além disso, foi feita uma entrevista semiestruturada com os docentes. Os resultados mostraram que os alunos tinham dificuldade em identificar os termos da divisão (dividendo, divisor, quociente e resto). A autora observou que os problemas criados pelos alunos tinham como base os livros didáticos utilizados por eles na escola, o que mostrou falta de profundidade no conteúdo e também de criatividade. Ao analisar as entrevistas dos docentes, a autora percebeu a dificuldade deles com a divisão, o que lhe permitiu inferir ser essa a causa das possíveis lacunas na aprendizagem dos alunos.

Silva G. (2007) investigou os possíveis fatores que podem interferir no desenvolvimento profissional de professores dos anos iniciais em uma formação continuada sobre frações. Para isso, foram realizados 16 encontros de quatro horas cada: três deles destinados à avaliação diagnóstica; nove, aos estudos de frações e diferentes metodologias; três, para entrevistas; e um, para reflexões sobre a formação. Sua pesquisa identificou alguns fatores que influenciam o desenvolvimento profissional docente, entre eles a existência de uma lacuna no seu conhecimento matemático, evidenciando a necessidade de mais estudos sobre os números racionais na formação inicial e continuada. A autora salienta a necessidade de constante reflexão sobre a prática docente para que os professores possam romper com suas concepções e crenças.

Rocha (2011) investigou os conhecimentos que os professores do Ensino Fundamental e do Ensino Médio possuíam sobre a Combinatória e seu ensino. A autora realizou entrevistas semiestruturadas com seis professores (dois dos anos iniciais do Ensino Fundamental, dois dos anos finais e dois do Ensino Médio). Esses docentes deveriam identificar os tipos de problemas combinatórios, suas resoluções e as possíveis estratégias de ensino. Como resultado, observou que os docentes confundiam problemas de arranjo com os de combinação, tanto ao lerem o enunciado, quanto ao analisarem as resoluções dos alunos. Verificou também que os professores dos anos iniciais acreditam que os enunciados dos problemas são o que os diferem e os professores com licenciatura em Matemática identificam os tipos de problemas por sua estrutura. A autora concluiu que é preciso que os docentes conheçam bem as estruturas combinatórias, as possíveis resoluções dos alunos e as estratégias de ensino.

Alencar (2012) realizou um estudo de caso em que investigou uma escola que obteve excelente avaliação no SARESP - Sistema de Avaliação e Rendimento do Estado de São Paulo - no ano de 2009. O objetivo de sua pesquisa foi identificar os aspectos do conhecimento profissional docente que influenciaram no bom desempenho dos alunos do $5^{\circ}$ ano do Ensino Fundamental na avaliação externa. Para isso utilizou questionários com situações-problema no Campo Conceitual Multiplicativo com protocolos de resoluções de alunos fictícios, entrevistas semiestruturadas sobre a prática docente e a análise de uma das situações com resolução desses alunos. A autora observou também aulas de diferentes professores e recolheu atividades desenvolvidas por eles. Em sua pesquisa, observou que os professores trabalham de forma colaborativa e também a existência de lacunas em seu 
DOI: http://dx.doi.org/10.20396/zet.v25i3.8647539

conhecimento matemático, o que a fez inferir que a formação docente deve ser reformulada em relação ao conhecimento específico do conteúdo.

Merlini (2012) investigou as contribuições e limites de uma formação contínua e colaborativa com professores dos anos iniciais do Ensino Fundamental sobre o Campo Conceitual Multiplicativo. A autora realizou um estudo de caso em que observou e acompanhou uma professora do $4^{\circ}$ ano do Ensino Fundamental em sua formação, na prática em sala de aula e em uma entrevista semiestruturada. A análise dos dados foi realizada por meio da observação dos diagnósticos coletados; da consolidação dos conhecimentos teóricos e práticos e da reflexão sobre as concepções e a didática da professora ao lidar com o Campo Conceitual Multiplicativo. A autora observou que houve uma melhora no conhecimento da docente sobre o Campo Conceitual Multiplicativo, mas que o tempo dessa pesquisa não foi suficiente para que houvesse maiores reflexões. Relata ainda que os resultados apontam contribuições e limitações nos aspectos didático, conceptual e cognitivo.

Santos (2012) investigou em sua tese as contribuições da formação contínua para professores dos anos inicias do Ensino Fundamental, tendo como eixo norteador a espiral ação-reflexão-planejamento-ação sobre o Campo Conceitual Multiplicativo. Para isso, a formação foi desenvolvida com três formadores e 14 docentes de uma escola da rede pública estadual de São Paulo em 16 encontros e realizada em duas etapas: diagnóstica e formativa. $\mathrm{O}$ autor percebeu que a formação estruturada ação-reflexão-planejamento-ação contribui para avanços e reflexões sobre concepções de ensino e aprendizagem sobre o Campo Conceitual

Multiplicativo, favorecendo os aspectos conceituais, didáticos, cognitivos e curriculares. Acrescentou ainda que práticas formativas sobre um determinado campo matemático são importantes, mas a análise, a reflexão e as ações compartilhadas em sala de aula tornam o processo formativo mais enriquecedor.

Oliveira (2014) realizou um estudo de caso no qual investigou os invariantes operatórios utilizados por professores que lecionam combinatória nos anos iniciais do Ensino Fundamental. Para a realização do estudo, foram utilizadas entrevistas semiestruturadas e questionário. Esse estudo considerou duas teorias: a Teoria dos Campos Conceituais e a Teoria Antropológica do Didático. A pesquisa identificou que os docentes consideravam o livro didático um material importante para o ensino, que desconheciam o currículo oculto e que não conheciam bem o conceito de combinatória.

Silva Junior (2015) investigou a formação continuada de professores do $4^{\circ}$ ano do Ensino Fundamental em uma escola de Fortaleza com o objetivo de promover a reflexão sobre a prática e o ensino de frações e também de potencializar o desenvolvimento profissional dos docentes. Para isso, observou as aulas dos professores e as utilizou na elaboração da formação, que abordou o conceito de frações e os saberes necessários para a prática docente. Após a formação, investigou também o comportamento profissional dos docentes e realizou com o grupo um replanejamento de suas ações pedagógicas. Como resultado da investigação, o autor pôde observar que houve reflexão e mudança de postura e planejamento por parte dos professores. 
DOI: http://dx.doi.org/10.20396/zet.v25i3.8647539

Sobre esse conjunto de pesquisas, realizamos uma metassíntese qualitativa, procurando identificar como foram utilizados os referenciais teóricos pelas pesquisas.

\section{Metassíntese qualitativa do uso do referencial teórico de Shulman}

Para metassintetizar o uso dos referenciais teóricos de Shulman pelas nove pesquisas, realizamos uma leitura, na íntegra, das dissertações e teses. Em seguida, fizemos o fichamento de cada trabalho, conforme modelo utilizado por Martins (2008), que contém: título da dissertação ou tese, autor, instituição, ano de defesa, número de páginas, palavraschave, resumo, objetivo, referencial teórico, análises e referenciais bibliográficos. Ao cruzar os dados, observamos semelhanças, diferenças e possíveis complementariedades que nos permitiram construir seis categorias:

I - Focaliza os três primeiros conhecimentos (conhecimento do conteúdo, conhecimento pedagógico e conhecimento curricular), definindo-os.

II - Denomina os sete conhecimentos definidos por Shulman, mas não os define.

III - Ressalta a importância do conhecimento específico do conteúdo.

IV - Complementa as ideias de Shulman com relação ao conhecimento pedagógico do conteúdo, contribuindo para a formação profissional docente.

V- Considera as ideias de Shulman com relação ao conhecimento específico do conteúdo, contribuindo para a formação dos docentes em Matemática.

VI - Traz à luz aspectos pouco abordados nos estudos de Shulman

Apresentamos aqui somente um recorte da tese de Alencar (2016) para evidenciar como foi realizada a metassíntese qualitativa. Dentre as categorias, expomos com detalhamento a primeira, pois apresenta os conhecimentos de Shulman $(1986,1987)$ mais utilizados pelas investigações, o que nos leva a refletir sobre quais os aspectos de seus estudos são ou não abordados e como são utilizados.

Observamos que Santos (2005), Campos (2007), Silva G (2007), Alencar (2012), Oliveira (2014) e Silva Junior (2015) apresentam a categoria I e a utilizam em suas análises. Portanto, focam suas investigações nos conhecimentos: específico do conteúdo, do conteúdo e curricular, não mencionando outros elementos que poderiam contribuir com a formação de professores, como por exemplo, o modelo-raciocínio-ação e os demais conhecimentos apresentados no artigo de Shulman de 1987.

Ao observarmos como cada conhecimento é abordado, identificamos que o Conhecimento do conteúdo é interpretado de modo semelhante pelas pesquisas. Selecionamos alguns trechos interpretados pelos autores das pesquisas a serem metassintetizadas, tais como: Santos (2005); Campos (2007); Silva G (2007); Alencar (2012); Oliveira (2014); e Silva Junior (2015). Salientamos que a metassíntese realizada na tese de Alencar (2016) faz a triangulação entre as interpretações das pesquisas selecionadas, a interpretação do autor original do estudo e a do pesquisador. 
DOI: http://dx.doi.org/10.20396/zet.v25i3.8647539

Assim, Santos (2005) ressalta a importância de o docente possuir uma boa compreensão do conteúdo:

o professor deve ter sólida e clara compreensão da disciplina que vai ensinar baseado em diferentes perspectivas e estabelecer relações entre os diversos tópicos do conteúdo da disciplina e entre sua disciplina e outras áreas do conhecimento(Santos, 2005, p.111).

Campos (2007) considera que o professor deve ter o conhecimento dos significados do conteúdo, compreendendo-o de diferentes modos:

conhecimento denominado por Shulman (1986) de conhecimento do conteúdo da disciplina é entendido pelo autor como a quantidade e a organização do conhecimento na mente do professor. Ele sugere que o conhecimento do conteúdo da disciplina deve envolver o conhecimento para ensinar não como um conjunto de regras relativas à aplicação do conteúdo, mas os conhecimentos relativos à natureza e aos significados dos conteúdos, o desenvolvimento histórico, os diversos modos de organizá-los.[...] o conhecimento do conteúdo da disciplina envolve tanto a compreensão de fatos, conceitos, processos e procedimentos de uma área específica de conhecimento quanto a concernente à construção dessa área. Desse modo, o professor deve compreender a disciplina que vai ensinar em diferentes perspectivas e estabelecer relações entre os vários tópicos do conteúdo disciplinar e entre sua disciplina e outras áreas do conhecimento. (Campos, 2007, p.57-58)

Silva G (2007) reafirma as considerações de Campos (2007) sobre o conhecimento aprofundado do conteúdo.

Conhecimento da matéria ensinada (subject knowledge matter): refere-se a conteúdos específicos da matéria que o professor leciona. Segundo o autor, "o professor necessita não somente entender que alguma coisa é assim; o professor precisa, além disso, compreender porque é assim, sobre que terrenos sua justificativa pode ser defendida e sob quais circunstâncias nossas crenças nessas justificativas podem ser enfraquecidas e igualmente escondidas". (Silva G., 2007, p. 60)

Alencar (2012, p.53) afirma, sem maiores explicações, que o docente deve "conhecer o conteúdo do qual deve ter domínio pleno a fim de ensinar".

Oliveira (2014, p.67) assume como a definição do "conhecimento do conteúdo como à forma como o estudante aprende determinado conteúdo".

Silva Junior (2015) mostra que os conhecimentos do professor têm especificidades:

Shulman (1986) considera que cada área do conhecimento tem uma especificidade própria que justifica a necessidade de estudar o conhecimento do professor, tendo em vista a disciplina que ele ensina. Ele identifica três vertentes no conhecimento do professor quando se refere ao conhecimento da disciplina para ensiná-la: o conhecimento do conteúdo da disciplina, o conhecimento didático do conteúdo da disciplina e o conhecimento do currículo" (Silva Junior, 2015, p 29).

Observamos que tais interpretações nos levam a identificar que Santos (2005) entende que o conhecimento do conteúdo é importante para que se possa compreender a disciplina de diferentes modos. Campos (2007) e Silva G (2007) também definem de modo similar a Santos (2005) no entanto ampliam o entendimento considerando que além da compreensão dos fatos e conceitos, deve saber os diferentes procedimentos da área. 
DOI: http://dx.doi.org/10.20396/zet.v25i3.8647539

De modo mais sucinto Alencar (2012) e Oliveira (2014) mencionam que o docente deve conhecer o conteúdo no qual deve ensinar, refletindo sobre como o aluno pensa sobre o conteúdo e o aprende. Silva Junior (2015) chama a atenção para a especificidade que os conhecimentos de cada área possuem.

O que é mencionado pelos autores vai ao encontro do que Shulman (1986) propõe em seus estudos: que o conhecimento do conteúdo se refere à organização desse conteúdo na mente do professor. Há, no entanto, várias outras formas de representá-lo, como o fazem alguns autores citados por Shulman (1986), como Bloom, Gagne, Schwab, Peters e Schwab para fundamentá-las.

O autor destaca ainda que o conhecimento do conteúdo vai além do domínio dos fatos ou conceitos, pois há necessidade de compreender as estruturas do conteúdo. Shulman (1986) recorre a Schwab (1978) para mostrar que essas estruturas são formadas por aspectos materiais e sintáticos. Considera-se aspectos materiais "a diversidade de organização dos conceitos e princípios para o entendimento do conteúdo". E os aspectos sintáticos, "o conjunto de formas em que verdade ou falsidade, validade ou invalidade estão estabelecidas" (Shulman, 1986, p. 9).

É importante também salientar que, para Shulman (1986), os professores devem conhecer bem o conteúdo, saber explicar a importância de aprendê-lo e como eles se relacionam com outros conteúdos.

Com isso, Shulman (1986) menciona que "o professor não precisa apenas entender que algo é assim; o professor deve ainda compreender por que é assim” (p.9). Ressalta ainda que o professor deve saber distinguir o conteúdo central do secundário.

Consideramos que o conhecimento do conteúdo é essencial para a formação de professores, visto que, uma base sólida de conhecimentos sobre o assunto a ensinar pode ajudar no planejamento das ações pedagógicas.

Em relação às interpretações realizadas sobre o conhecimento pedagógico, observamos como os autores o interpretam.

Para Santos (2005, p.111), “o conhecimento pedagógico é uma combinação desencadeada entre o conhecimento da disciplina e do modo de ensinar, tornando assim a disciplina compreensível para o aluno".

Campos (2007) afirma que:

Em relação ao ensino da matemática, os professores devem ter conhecimento sobre os conceitos, as operações de algoritmos, as conexões entre os procedimentos de diferentes algoritmos, o subconjunto do sistema numérico, a compreensão dos erros dos alunos e a apresentação do currículo. Os professores com uma boa compreensão do conteúdo conseguem fazer representações múltiplas de um conceito, compreendem os princípios aritméticos básicos e as múltiplas conexões entre os conceitos em outros conjuntos aritméticos. Embora uma compreensão da matéria seja necessária, não é condição suficiente para que o professor seja capaz de ensinar. Os professores devem encontrar formas de comunicar conhecimentos para os outros [...] (Campos, 2007, p. 
58)

DOI: http://dx.doi.org/10.20396/zet.v25i3.8647539

Silva G (2007) considera as relações existentes entre conteúdo para seu ensino:

O conhecimento pedagógico do conteúdo é uma "mistura especial" (relação) entre o conteúdo a ensinar e a pedagogia que pertence unicamente aos professores e que constitui a sua forma especial de compreensão de como tópicos particulares, problemas ou temas são organizados, representados e adaptados aos interesses e às capacidades dos alunos e apresentados para o ensino (Silva G, 2007, p.60-grifo nosso).

Nesta citação, Silva G (2007) parece considerar a pedagogia com uma estratégia de ensino. O que não nos aparece coerente com o conjunto dos construtos teóricos constitutivo da pedagogia. Além disso, o referido autor atribuir a Shulman (1986) a palavra "mistura" que parece ir de encontro com o fato de que a relação entre o conteúdo a ensinar e a pedagogia não é mecânica.

No mesmo sentido, Alencar (2012) estabelece relações entre conteúdo e ensino e enfatiza a experiência da prática. Explica como "o professor transmite os conteúdos e quais estratégias utilizam para que o aluno aprenda, isto é, mostra a experiência prática” (Alencar, 2012, p.53).

E Oliveira (2014) menciona a interação do conteúdo com os modos de ensinar:

O conhecimento do conteúdo e sobre o ensino é a interação e a forma como esse conhecimento será trabalhado e as variedades de formas de organizar ideias-chave e conceitos para os alunos, ou seja, combina o saber sobre o ensino e o saber sobre o conteúdo (Oliveira, 2014, p.67).

Silva Junior (2015) enfatiza a importância de o conhecimento pedagógico do conteúdo ter uma aproximação com a realidade dos alunos. Salienta que esse conhecimento é formado pelos conhecimentos do conteúdo, dos estudantes e do currículo. O autor menciona: "Em âmbito geral, o Conhecimento do Conteúdo e o dos Estudantes têm relação com a aproximação do professor com as peculiaridades dos seus alunos ou dos grupos de estudantes" (Silva Júnior, 2015, p.43).

Para Shulman (1986), o conhecimento pedagógico do conteúdo vai além do conhecimento do conteúdo para o ensino. É preciso conhecer os tópicos mais abordados da área, as diferentes maneiras de apresentar as ideias, as diferentes analogias, ilustrações, explanações e demonstrações. Esses aspectos permitem que o conteúdo seja melhor compreendido pelos estudantes.

O autor salienta que o professor deve saber quais são os assuntos mais fáceis e difíceis a serem ensinados e quais concepções os alunos trazem sobre determinado conhecimento que podem ser utilizados como ponto de partida. Para tanto, inferimos que é preciso que os professores disponham de conhecimentos necessários para complementar e auxiliar as aprendizagens do aluno, assim como esclarecer os equívocos que se apresentarem.

Shulman (1986) salienta ainda que pesquisas realizadas sobre o ensino e a aprendizagem vêm abordando as concepções equivocadas dos estudantes e discutindo maneiras de aprimorar a aprendizagem e superar os equívocos. Deve-se, portanto, ter como foco investigativo o conhecimento pedagógico necessário para cada situação. 
DOI: http://dx.doi.org/10.20396/zet.v25i3.8647539

O conhecimento pedagógico, assim como relatado pelas pesquisas e por Shulman, é importante para as atividades de planejamento e ensino, no entanto há que se notar que essas devem estar articuladas com outros conhecimentos não citados pelas investigações como, por exemplo: o conhecimento dos alunos e suas características, assim como também dos contextos educativos.

Com relação ao conhecimento curricular e às abordagens realizadas pelas pesquisas, também identificamos semelhanças, quando Santos (2005, p.112) considera o conhecimento curricular como o conteúdo do programa, as articulações verticais do conteúdo e as escolhas curriculares do conteúdo.

Com a mesma interpretação, mas complementando Santos (2005), Campos (2007) considera que, além dos conteúdos do programa, o conhecimento curricular necessita também da compressão dos mesmos. Campos (2007, p.60) considera que o professor deve conhecer todo os conteúdos curriculares, assim como também pensar quais materiais se podem utilizar para ensinar tais conteúdos, traçando possíveis diretrizes de trabalho ao professor.

Silva G. (2007, p.60) menciona a utilização dos materiais curriculares e do conhecimento das teorias que está implícito no currículo. Para a autora, esse conhecimento pode permitir identificar alternativas curriculares para o ensino e de modo implícito está relacionado aos princípios de ensino e aprendizagem.

Para Alencar (2012 p. 53), o conhecimento curricular "são as especificações e os detalhes sobre o currículo proposto, ou seja, as razões morais e éticas".

Oliveira (2014, p.67) considera que o conhecimento curricular "é o conhecimento dos materiais curriculares e sua relação com o ensino".

Silva Junior (2015, p.44-45) observa que o conhecimento curricular é formado por conteúdos propostos e desenvolvidos de modo particular para cada realidade. O autor considera ainda que o modo como é organizado o currículo influencia como será o direcionamento das atividades de ensino e aprendizagem.

Assim diante das interpretações, ao discorrer sobre o conhecimento curricular, Shulman (1986) considera que se os conhecimentos pedagógicos não fazem parte da formação de professores, quiçá o conhecimento curricular.

Para o autor:

O currículo é representado por toda gama de programas concebidos para o ensino das disciplinas específicas e dos temas em um determinado nível, pela variedade de materiais didáticos disponíveis em relação a esses programas e pelo conjunto de características que servem tanto como indicações como contra indicações para a utilização em currículo particular ou de materiais em circunstâncias especiais. (Shulman, 1986, p.10, tradução nossa)

Observa que, a exemplo do médico, que deve conhecer todas as alternativas de tratamento para o paciente doente, espera-se que o professor tenha os entendimentos das alternativas para o ensino curricular. Acrescenta ainda que há dois tipos de aspectos 
DOI: http://dx.doi.org/10.20396/zet.v25i3.8647539

complementares de conhecimento curricular:

- $\quad$ Conhecimento curricular lateral, que "é a capacidade de o professor relacionar o conteúdo de determinado curso ou aula com temas ou questões que estão sendo discutidos em outros grupos da escola". (Shulman, 1986, p.10, tradução nossa)

- Conhecimento curricular vertical, que "é a familiaridade do professor com os temas e questões que têm sido e serão ministrados na mesma área temática, durante o ano anterior e mais tarde, na escola e com os materiais neles relacionados" (Shulman, 1986, p.10, tradução nossa).

Notamos que Santos (2005), Campos (2007), Silva G (2007), Alencar (2012), Oliveira (2014) e Silva Junior (2015) interpretam, de modo semelhante ao que é exposto por Shulman (1986). Acreditamos que esses autores se aprofundam nos três conhecimentos, porque utilizam o artigo de 1986 como base teórica. Temos como hipótese que, talvez, se as pesquisas tivessem utilizado o artigo de Shulman (1987) - que se refere aos outros quatro conhecimentos: i) pedagógico geral; ii) dos alunos e suas características; iii) dos contextos educativos e; iv) dos objetivos, das finalidades, dos valores educativos e dos fundamentos filosóficos e históricos - poderiam contribuir significativamente para a ampliação da reflexão sobre os aspectos formativos.

\section{Metassíntese qualitativa do uso do referencial teórico de Vergnaud}

Dos dados das pesquisas, emergiram categorias sobre os elementos explicitados da Teoria dos Campos Conceituais (TCC) e do Campo Conceitual Multiplicativo. Apresentamos oito categorias relativas ao seu emprego pelas investigações:

1) Apresenta a definição da Teoria dos Campos Conceituais.

2) Considera um campo conceitual como um conjunto de situações propostas aos estudantes.

3) Interpreta a noção de esquema na Teoria dos Campos Conceituais.

4) Considera o esquema como organização invariante em uma classe de situações.

5) Apresenta a formação de conceitos pela terna de conjuntos: S - Situações; I -

Invariantes; e R - Representações simbólicas.

6) Dá grande atenção à construção de conceitos matemáticos.

7) Detalha a apresentação do Campo Conceitual Multiplicativo.

8) Traz noções sobre o Campo Conceitual Aditivo (cálculo relacional e cálculo numérico) para o Campo Conceitual Multiplicativo.

Assim como já exposto na seção anterior, apresentamos aqui somente um recorte do estudo original de Alencar (2016) para mostrar como foi realizada a metassíntese qualitativa. Dentre as categorias, selecionamos a primeira, por ser a mais utilizada pelas investigações selecionadas e, a nosso ver, poderia explicitar o modo como as pesquisas interpretaram o referencial teórico de Vergnaud.

Pudemos observar que as definições apresentadas pelas pesquisas se assemelham aos 
DOI: http://dx.doi.org/10.20396/zet.v25i3.8647539

estudos de Vergnaud. Santos (2005), Campos (2007), Silva G (2007), Rocha (2011), Alencar (2012), Merlini (2012), Santos (2012), Oliveira (2014) e Silva Junior (2015) apresentam em suas pesquisas a definição da Teoria dos Campos Conceituais. Consideramos assim que as investigações dão importância para a compreensão do que é a Teoria dos campos conceituais para o estudo do Campo Conceitual Multiplicativo.

Notamos que duas das pesquisas (Santos, 2005 e Campos, 2007) tratam da noção de esquema, com interpretações equivalentes em relação aos aspectos de ruptura e semelhança, como mostrado a seguir:

Santos (2005) cita o objetivo da Teoria dos Campos Conceituais:

é possibilitar uma estrutura consistente às pesquisas sobre atividades cognitivas, em especial com referência à aprendizagem da matemática, permitindo situar e estudar as filiações e as rupturas entre conhecimentos na perspectiva de seu conteúdo conceitual, isto é, estudar as teias de relações existentes entre os conceitos matemáticos. (Santos, 2005, p.28)

Campos (2007) corrobora as interpretações realizadas por Santos (2005), abordando de modo mais sucinto, o objetivo da teoria, quando afirma que a referida teoria

tem como objetivo propiciar uma estrutura coerente sobre as atividades cognitivas, em especial com referência à aprendizagem da matemática, permitindo situar e estudar as filiações e rupturas entre conhecimentos na perspectiva de seu conteúdo conceitual (Campos, 2005, p. 29).

Silva G (2007), Rocha (2011), Merlini (2012) e Santos (2012) observam que a aprendizagem de um campo conceitual é influenciada por diferentes fatores; por isso, a importância do trabalho com as diferentes situações.

Observamos que, para Silva G (2007), o desenvolvimento da Teoria dos Campos Conceituais emerge de diferentes situações:

A Teoria dos Campos Conceituais considera que existe uma série de fatores que influenciam a construção dos conceitos e que o conhecimento conceitual deve emergir de determinadas situações. Vergnaud usa o termo "situação" com o sentido de tarefa a ser executada pelo aluno e considera que a dificuldade de uma tarefa não é nem a soma, nem o produto da dificuldade das diferentes subtarefas. É claro, contudo, que o fracasso em uma subtarefa provoca o fracasso global (Silva G, 2007, pp.76-77).

Rocha (2011) define campos conceituais estando relacionado com as situações como mencionado por Vergnaud (1990)

Vergnaud defende que o conhecimento se organiza em campos conceituais, sendo campo conceitual definido como um conjunto de situações, cujo domínio necessita de uma variedade de conceitos, de procedimentos e representações simbólicas em estreita ligação. A aprendizagem de conceitos dentro de um campo conceitual não ocorre em meses ou mesmo em anos. Para que isso aconteça, torna-se necessário estudar novos problemas e novas propriedades ao longo de vários anos. A construção de conceitos matemáticos se dá por meio da proposta de uma gama de situações que proporcionem a oportunidade para os alunos reconhecerem os invariantes e utilizarem variadas representações simbólicas, permitindo aos mesmos a visão do conhecimento matemático com sentido e significados (Rocha, 2011, p.38). 
DOI: http://dx.doi.org/10.20396/zet.v25i3.8647539

Merlini (2012) focaliza sua definição no desenvolvimento dos conceitos:

Desse modo, a Teoria dos Campos Conceituais supõe que o âmago do desenvolvimento cognitivo é a conceitualização. É ela a pedra angular da cognição. Logo, deve-se dar toda atenção aos aspectos conceituais dos esquemas e à análise conceitual das situações para as quais os estudantes desenvolvem seus esquemas na escola ou fora dela (Merlini, 2012, p.53).

Observamos que Santos (2012) enfatiza a necessidade de interação entre as situações de ensino e de aprendizagem para que haja o desenvolvimento do conceito.

Ao estudar a Teoria dos Campos Conceituais, desde a sua formulação até o seu desenvolvimento, pode-se observar que Vergnaud enfatiza, por um lado, que, para a formação de um conceito, é necessário manter uma estreita interação entre ele e uma diversidade de situações. Por outro lado, uma situação, por mais simples que ela se apresente, envolve vários conceitos. Assim sendo, não faz sentido referir-se à formação do conceito, mas sim à formação de um campo conceitual, cuja apropriação requer o domínio de diversos conceitos de naturezas distintas (Santos, 2012, p.89).

Alencar (2012) diz que a Teoria dos Campos Conceituais (TCC) apresenta alguns princípios para o desenvolvimento e a aprendizagem cognitiva:

A TCC é cognitivista. Para o autor, seu estudo pretende ser um marco, uma vez que apresenta "[...] alguns princípios de base para o estudo do desenvolvimento e da aprendizagem de competências complexas, especialmente as que se referem às ciências e às técnicas" (Alencar, 2012, p.62).

Oliveira (2014) afirma que os conceitos são desenvolvidos durante as experiências:

Essa teoria assume como pressuposto que o conhecimento se constrói e se desenvolve no tempo, em interação adaptativa com as situações. Segundo Vergnaud (2009), quando o indivíduo confronta novas situações, utiliza os conhecimentos adquiridos em suas experiências passadas (Oliveira, 2014, p.57).

Silva Junior (2015) corrobora a citação anterior e a complementa, mencionando a importância de considerar os conhecimentos prévios:

A TCC versa sobre o processo de conceituação do que é real. É uma teoria psicológica que admite a organização do conhecimento em campos conceituais, como explica Vergnaud (1990, 2010). Para ele, o sujeito se apropria desses campos ao longo da vida por meio da experiência, maturidade e aprendizagem. Podemos ressaltar, ainda, que os conhecimentos prévios assumem papel fundamental, quer como precursores de novos conhecimentos, quer como elementos de ruptura na construção do conhecimento. Torna-se necessário identificar sobre quais conhecimentos prévios a criança pode se apoiar para aprender, porém é muito importante distinguir quais as rupturas necessárias (Silva Junior, 2015, p. 34).

Pudemos perceber que cada autor utiliza as ideias de Vergnaud (1990), ressaltando pontos que foram significativos para suas pesquisas, principalmente quando os autores tratam do desenvolvimento cognitivo de conceitos que são realizados por meio de esquemas e promovidos ao longo do tempo. Nesse processo de desenvolvimento do conhecimento há filiações e rupturas, que são influenciadas por diferentes fatores e situações, sendo organizados em campos conceituais.

O objetivo da Teoria dos Campos Conceituais é "compreender as relações e as 
DOI: http://dx.doi.org/10.20396/zet.v25i3.8647539

rupturas nos conhecimentos das crianças e dos adolescentes" (Vergnaud, 1990, p.135, tradução nossa). Assim, essa Teoria nos permite conhecer os conceitos utilizados pelos alunos na resolução de situações-problema.

O autor destaca a importância de entender o conhecimento do "saber fazer, que são as competências que se desenvolvem ao longo da vida" (Vergnaud, 1996, p.200), e do saber expressado, que "é aquele que é explicitado e utilizado nas situações-problema" (Vergnaud, 1990, p.135). Vergnaud acrescenta ainda que a TCC não se restringe somente aos conhecimentos matemáticos. Apesar de ter sido elaborada e discutida a partir de alguns conteúdos da Matemática, essa teoria pode ser utilizada em outras áreas.

A TCC traz algumas discussões e definições sobre conceitos e esquemas. Mostra que um esquema só pode ser definido em um ambiente de aprendizagem e ensino, isto é, por meio de situações-problema.

Essa Teoria auxilia a identificação dos invariantes, dos objetos matemáticos, das propriedades desses objetos, das relações entre eles e dos teoremas. Ajuda na reflexão, nas inferências, na antecipação dos efeitos e no controle de ações.

O autor acredita que essas discussões sobre como o conhecimento se desenvolve e as características de um campo conceitual são importantes para a Psicologia, a Didática e a História das Ciências.

Notamos que, para os autores das pesquisas analisadas, é importante definir a Teoria dos Campos Conceituais. Neste aspecto, percebemos que eles o fazem de modo semelhante ao que Vergnaud (1990) fez em seus estudos. Encontramos nas interpretações somente um complemento à definição da TCC mencionada por Vergnaud (1990) realizado por Silva Junior (2015) que evidencia que a Teoria deve considerar os conhecimentos prévios dos alunos. $\mathrm{O}$ autor menciona que "Torna-se necessário identificar sobre quais conhecimentos prévios a criança pode se apoiar para aprender" (p.34), ao relatar sobre os esquemas citados por Vergnaud (1990). Assim, o autor menciona que os esquemas já adquiridos devem ser estimulados aos novos esquemas para que haja o desenvolvimento da aprendizagem. Vergnaud $(1990,1998)$ não discute em seu estudo sobre os conhecimentos prévios, mas sim nas rupturas que devem ocorrer nos esquemas já estabelecidos e novos para que ocorre a aprendizagem. Inferimos assim que este aspecto é um possível complemento à teoria, visto que não encontramos indícios que tal aspecto é mencionado por Vergnaud $(1990,1988)$ como conhecimentos prévios em seus estudos.

\section{Algumas conclusões e considerações finais}

Constatamos que os aspectos dos estudos de Shulman, na Categoria I "Focaliza os três primeiros conhecimentos (do conteúdo, do pedagógico e curricular), definindo-os", são evidenciados pelas pesquisas de modo semelhante ao que Shulman (1986) expôs em sua primeira obra. Não encontramos, em nossa metassíntese, diferenças nas interpretações dos autores das pesquisas analisadas com relação ao estudo de Shulman. Notamos que as reflexões tecidas por Shulman (1986) influenciaram as pesquisas por nós analisadas, principalmente no que tange ao uso dos três tipos de conhecimentos (do conteúdo, 
DOI: http://dx.doi.org/10.20396/zet.v25i3.8647539

pedagógico e curricular). Mencionamos ainda que se as complementações tecidas por Shulman (1987) tivessem sido consideradas, os autores das pesquisas revisitadas neste estudo teriam provavelmente também incorporado em sua análise quatro tipos adicionais de conhecimento: 1) Pedagógico geral; 2) dos alunos e suas características; 3) dos contextos educativos e 4) dos objetivos, das finalidades, dos valores educativos e dos fundamentos filosóficos e históricos.

Quanto à metassíntese qualitativa relativa ao uso do referencial teórico de Vergnaud, referente à Categoria I “Apresenta a definição da Teoria dos Campos Conceituais”, notamos que as pesquisas dão importância para a definição dos Campos Conceituais e aos elementos que a compõem, ao invés de aprofundar o Campo Conceitual Multiplicativo. Essa pouca ênfase ao campo multiplicativo deve-se, provavelmente, ao fato de o artigo mais utilizado do autor pelas investigações foi o de 1990 que apresenta de modo detalhado a TCC e não especificamente o Campo Conceitual Multiplicativo que foi apresentado no artigo de 1988.

Verificamos também complementariedades à Teoria de Vergnaud em pesquisas que exemplificaram aspectos da TCC, como Silva Junior (2015) que apresenta a relação da Teoria com os conhecimentos prévios dos alunos.

Salientamos, além disso, que há aspectos importantes dos estudos que não foram abordados pelas pesquisas, como: o modelo de raciocínio e ação de Shulman e o aprofundamento das situações-problema apresentadas por Vergnaud, que podem ser mais utilizados em pesquisas futuras.

Em relação às contribuições deste estudo para a formação de professores sobre o Campo Conceitual Multiplicativo, foi possível identificar os aspectos da teoria que foram e não foram abordados pelas pesquisas revisadas. Há pontos importantes nos referenciais teóricos como as formas de conhecimento docente e o modelo pedagógico de raciocínio e ação mencionados por Shulman $(1987,2005)$ que poderiam ser abordados na formação de professores. E no Campo Conceitual Multiplicativo, vê-se a necessidade do aprofundamento e entendimento das situações-problema abordadas por Vergnaud.

Concluímos que ambos os referenciais teóricos - Shulman e Vergnaud - tecem considerações sobre a importância de identificar e compreender como se forma um conceito, conhecendo as representações, as inferências e as diferentes situações de um campo conceitual. Conforme Shulman (1986), o conhecimento específico do conteúdo é importante para que o professor possa analisar as resoluções dos alunos sob diferentes enfoques. De modo semelhante, Vergnaud (1990) nos propicia reflexões e compreensões sobre o papel das diferentes situações relativas a um Campo Conceitual, que nos ajudam perceber e analisar diferentes representações, inferências e estratégias utilizadas pelos alunos na formação de um conceito. Assim, inferimos que o estudo da Teoria dos Campos Conceituais de Vergnaud na formação de professores pode colaborar com o desenvolvimento e/ou aprimoramento do conhecimento do conteúdo e pedagógico necessários à docência conforme menciona Shulman (1986).

Observamos, por outro lado, que as pesquisas, apesar de se debruçarem sobre o Zetetiké, Campinas, SP, v.25, n. 3, set./dez.2017, p.534-554

ISSN 2176-1744 
DOI: http://dx.doi.org/10.20396/zet.v25i3.8647539

Campo Conceitual Multiplicativo, apresentam pouco aprofundamento no estudo das diferentes situações-problema nas práticas de formação docente. Assim, vemos a necessidade de se realizar estudos que apresentem as diferentes situações-problema no Campo Conceitual Multiplicativo envolvendo contextos formativos.

\section{Referências}

Alencar, E. S. (2016). Formação de professores sobre o Campo Conceitual Multiplicativo: referenciais teóricos em pesquisas. Tese de Doutorado, São Paulo: Pontifícia Universidade Católica de São Paulo. Brasil

André, M. D. (2002). Formação de professor no Brasil (1990 -1998) (Serie Estado do Conhecimento $6^{\mathrm{a}}$ ed.). Brasília: MEC/ Inep /Comped.

Banco de teses. (2016). Retirado em julho, 2016, de: http://www.bancodeteses.capes.gov.br

Brzezinski, I. (2006). Formação de profissionais da educação (1997-2002) (Vol. Série estado do conhecimento n.10). Brasilia: MEC/Inep/Comped.

Fiorentini, D. (2013). Investigação em Educação Matemática desde a perspectiva acadêmica e profissional: desafios e possibilidades de aproximação. Cuadernos de Investigación y Formación en Educación Matemática, 8 (11), 61-82.

Maia, M.G. B. (2013) Alfabetização matemática: aspectos concernentes ao processo na perspectiva de publicações brasileiras. Tese ( Doutorado em EducaçãoMatemática). Pontifícia Universidade Católica de São Paulo: São Paulo.Brasil

Maranhão , M. C. S. A., \& Manrique A. L. (2014). Pesquisas que articulam a Teoria das Situações Didáticas em Matemática com outras Teorias: concepções sobre aprendizagem do professor. Revista Perspectivas da Educação Matemática. 7, Número Temático.

Martins, A. M. (2008) Uma metanálise qualitativa das dissertações sobre equações algébricas no ensino fundamental. Dissertação ( Mestrado em Educação Matemática) Pontifícia Universidade Católica de São Paulo: São Paulo.Brasil

Melo, M. V., \& Fiorentini, D. (2008). A pesquisa brasileira sobre formação de professores que ensinam matemática: diversidades teórico-metodológicas; desafios epistemológicos e a busca de identidade. EBRAPEM, Encontro Brasileiro de Estudantes de Pósgraduação em Educação Matemática: Quais os próximos desafio em Educação Matemática.

Mendes, K. V., \& Romanovski, J. P. (2006). Formação continuada de professores: os modelos com base na racionalidade técnica. Anais de evento Educere, pp. 2587-2595.

Romanowski, J. P., \& Ens, R. T. (2006). As pesquisas denomindas do tipo estado da arte em Educação. Revista Diálogo Educacional, 6(19), 37-50. 
DOI: http://dx.doi.org/10.20396/zet.v25i3.8647539

Shulman, L. (1986). Those who understand : knowledge growth in teaching. Education Researcher, 15(2), 4-14.

Vergnaud, G. (1990). La théorie des champs conceptuels. Récherches em Didactique des Mathematiques, 23(10), 133-170.

Vergnaud, G. (1997). Le Moniteur de Mathematique. Paris: Editions Nathan.

Vergnaud, G. (2009). A criança, a matemática e a realidade. (Traduação de M. L. Moro) Curitiba: UFPR.

\section{APÊNDICE 1: Relação de dissertações/teses do corpus de análise deste estudo}

Alencar, E. S. (2012). Conhecimento Profissional Docente de Professores do $5^{\circ}$ ano em uma escola com bom desempenho em Matemática: o caso das estruturas multiplicativas. Dissertação de Mestrado Educação Matemática, São Paulo: Universidade Bandeirantes. Sao Paulo, Brasil.

Campos, E. G. (2007). As dificuldades na aprendizagem da divisão: análise da produção dos erros dos alunos do ensino fundamental e sua relação com o ensino praticado pelos professores Dissertação de Mestrado em Educação. Universidade Católica Dom Bosco: Campo Grande.

Merlini, V. L. (2012). As pontencialidades de um processo formativo para a reflexão na sobre a prática de uma professora das séries iniciais: um estudo de caso Tese de Doutorado em Educação Matemática. Pontifícia Universidade Católica de São Paulo: São Paulo.Brasil

Oliveira, E. G. (2014). Raciocínio combinatório na resolução de problemas nos anos iniciais do ensino fundamental:um estudo com professores. Dissertação de Mestrado em Educação Matemática. Pontifícia Universidade Católica de São Paulo: São Paulo.

Rocha, C. A. (2011). A formação docente e o ensino de problemas combinatórios: diversos olhares, diferentes conhecimentos Dissertação de Mestrado em Educação. UFPE: Recife.Brasil.

Silva, A. F. G.(2007) O desafio do desenvolvimento profissional docente: análise da formação continuada de um grupo de professores das séries iniciais do ensino fundamental, tendo como objeto de discussão o processo do ensino e aprendizagem de frações. Tese de Doutorado em Educação Matemática. PUC-SP São Paulo. Brasil.

Santos, A. D. (2005). O conceito de fração em seus diferentes significados: um estudo diagnóstico junto a professores que atuam no Ensino Fundamental Dissertação de Mestrado em Educação Matemática. PUCSP: São Paulo.Brasil.

Santos, A. (2012). Processo de formação colaborativa co foco no Campo Multiplicativo: um caminho possível com professoras polivalentes. Tese de Doutorado em Educação Matemática. PUCSP: São Paulo.Brasil. 
DOI: http://dx.doi.org/10.20396/zet.v25i3.8647539

Silva Junior, F. J. (2015) Intervenções didáticas no ensino de frações e a formação de professores. Dissertação de Mestrado em Educação Matemática. Universidade Anhanguera. São Paulo Brasil 